Journal of Biotechnology and Strategic Health Research

\author{
Research Article / Araştırma Makalesi
}

http://dergipark.org.tr/tr/pub/bshr

\title{
Türkiye’de COVID-19 Salgınına Yönelik Epidemik Gelişmeler ve Diğer Ülkelerle Olan Benzerlikleri: Tanımlayıcı Bir Çalışma
}

\author{
Epidemic Update of COVID-19 in Turkey and Similarity with Other Countries: \\ A Descriptive Study
}

\section{\eli Durmuș}

Marmara Üniversitesi, Sağlık Bilimleri Enstitüsü, Maltepe, İstanbul

ORCID ID: Veli Durmuş 0000-0001-6124-6109

*Sorumlu Yazar / Corresponding Author: Veli Durmuş, e-posta / e-mail: velidurmus@marun.edu.tr

Geliş Tarihi / Received: 15-05-2020 Kabul Tarihi / Accepted: 23-04-2020 Yayın Tarihi / Online Published: 31-08-2020

Atıf Gösterimi/How to Cite: Durmuş V. Türkiye’de COVID-19 Salgınına Yönelik Epidemik Gelişmeler ve Diğer Ülkelerle Olan

Benzerlikleri: Tanımlayıcı Bir Çalışma, J Biotechnol and Strategic Health Res. 2020;4(2):134-142

\begin{abstract}
Özet
Amaç İlk olarak Çin’de tespit edilen COVID-19 salgını kısa sürede, Türkiye’de dahil, 200'den fazla ülkede raporlanmıştır. Bu durum toplum sağlığı açısından büyük bir tehdit oluşturmaktadır. Her ülkede salgının neden olduğu etkiler farklı olmaktadır. Bu çalışma ile Türkiye’deki ve en çok doğrulanmış vaka rapor edilen ülkelerdeki COVID-19 salgınına bağlı parametrelerin tanımlayıcı olarak karşılaştırılması amaçlanmıştır.

Materyal ve Ülkelere göre ilk COVID-19 vakasının tespit edilmesinden sonraki 57 günlük sürede gelișen vakalara yönelik, 22 Ocak - 6 Mayıs 2020 tarihleri

Metod arasındaki ilgili veri seti Johns Hopkins Üniversitesine bağlı resmi veritabanından detaylı bir araștırma ile elde edilmistir. Ayrıca Dünya Sağlık Örgütü’nün yapmış olduğu günlük raporlar da çalışmaya dahil edilmiştir. Ülkelere göre ilk rapor edilen vaka tarihi tanımlanmış ve sonraki 57 günlük salgın sürecine ait veri seti oluşturulmuştur.

Bulgular Ocak 2020 sonunda dünya genelinde vaka artış oranı aniden yükselmesine rağmen, sonraki aylarda günlük vaka artıș oranı düșme eğilimi göstermistir. Toplam vaka sayıları farklı olmakla birlikte, Türkiye’nin vaka artıs eğrisi İtalya ve Amerika Birlesik Devletleri ile benzerlik göstermektedir. İlk 57.günde vaka ölüm hızı Türkiye’de \%2,72 ile Rusya $(\% 0,38)$, İngiltere $(\% 1,57)$ ve Almanya $(\% 0,42)$ gibi ülkelerden daha fazladır. İyileşen hasta sayısının ölen sayısına olan orana bakıldığında en yüksek ülkenin Almanya olduğu görülmektedir. Türkiye'de bu oran daha 1lımlı gibi görünmesine rağmen, İngiltere’de oldukça düşüktür.

Sonuç Vaka sayısının artmasıyla ülkelerde rapor edilen epidemik parametrelerde hızla değișmektedir. Özellikle karar vericilerin daha etkili vaka gözlem, takip ve kontrol sistemleri oluşturarak toplumsal ve bireysel düzeyde hastalığın etkilerini azaltmak için önlemler alması gereklidir.

Anahtar Koronavirüs, COVID-19, salgın, Türkiye.

kelimeler
\end{abstract}

Abstract

Aim COVID-19 outbreaks firstly observed in mainland in China have been reported in more than 200 countries, including Turkey in a short period. This makes a serious threat to the world in terms of public health. Various effects caused by the epidemic are different in each country. The present study was aimed to compare the COVID-19 epidemic parameters in Turkey with countries with the most reported confirmed cases around the world.

Material and The relevant data set by country between 22 January and 6 May 2020, associated with the cases that 57-day after the first COVID-19 report, was obtained from

Method a detailed research from the official database of Johns Hopkins University. Additionally, daily reports announced by World health Organization are included to the study. The first reported case by country was identified and a data set for the next 57-day epidemic progress was created.

Results Although the number of confirmed cases sharply increased worldwide at the end of January 2020, the daily growth rate tended to decrease in the following months. The growth curve of Turkey was similar to Italy and the United States, however, the number of confirmed cases was different. Case fatality rate on the first 57-day, Turkey with 2,72\% more higher than such countries Russia (\%0,38), the United Kingdom (\%1,57), and Germany (\%0,42). Considering the ratio of the number of recovered patients to the number of deaths, it is seen that the highest country is Germany. Though it seems like a more moderate rate in Turkey, it is lower in the United Kingdom.

Conclusion With the increasing number of cases, epidemic parameters of the outbreak in countries are changing rapidly. In particular, decision makers need to take measures to mitigate the impact of the pandemic at the social and individual level by using effectively national surveillance, monitoring and control systems.

Key words Coronavirus, COVID-19, outbreak, Turkey. 


\section{GIIRIŞ}

İlk olarak 2019 yılının Aralık ayının başlarında, Çin’in Hubai eyaletinde yer alan Wuhan adlı şehirde ortaya çıktığ 1 tespit edilen koronovirüs enfeksiyonu (COVID-19), kısa sürede dünya geneline yayılmıştır. ${ }^{1}$ Ciddi akut solunum yetmezliği sendromuna yol açan bu hastalık, 6 Mayıs 2020 tarihi itibariyle 3,5 milyondan fazla kişiye bulaşarak 250 binden fazla kişinin ölümüne yol açmıştır. ${ }^{2}$ Hastalığın ilk bulaştığı Wuhan şehrinde her ne kadar şehir giriş ve çıkışları kontrol altına alınmış olsa da, Çin dışındaki ülkelerde gözlenen vaka sayıları 26 Şubat 2020 tarihi itibariyle katlanarak artmış ve Çin’deki vaka sayısını fazlasıyla geçmiştir., 25 Nisan 2020 itibariyle dünya genelinde (Çin hariç) doğrulanmış toplam vaka sayısı 2.719 .897 ve doğrulanmış toplam ölüm sayısı 187.705 olarak raporlanmıştır. Çin’de ise toplam 84.325 vaka sayısı ve 4642 toplam ölen hasta sayısı bildirilmiştir. ${ }^{5}$

Salgının çeşitli kıtalarda yer alan 200'den fazla ülkede etkilerini önlemeye yönelik ciddi derecede sosyal, ekonomik ve tıbbi tedbirlerin alınmasına ihtiyaç duyulmuştur. Ancak bütün bu önlemlere rağmen, 6 Mayıs 2020 tarihinde doğrulanmış birikimli vaka sayısı sırasıyla en çok Amerika Birleşik Devletleri’nde (1.200.000'den fazla), İspanyảda (220 binden fazla), İtalya'da (214 binden fazla) ve Fransa'da (172 binden fazla) görülmüştür (Şekil 1). Türkiye'de ise ilk doğrulanmış vaka, 11 Mart 2020 tarihinde yalnızca bir kişi olarak rapor edilmesine rağmen, kısa sürede büyük bir artışla 6 Mayıs 2020 itibariyle Çin (84 binden fazla) ve İran’ı (100 binden fazla) geride bırakarak, 131.744 ile en çok vakaya sahip 8. ülke olmuştur. ${ }^{6}$

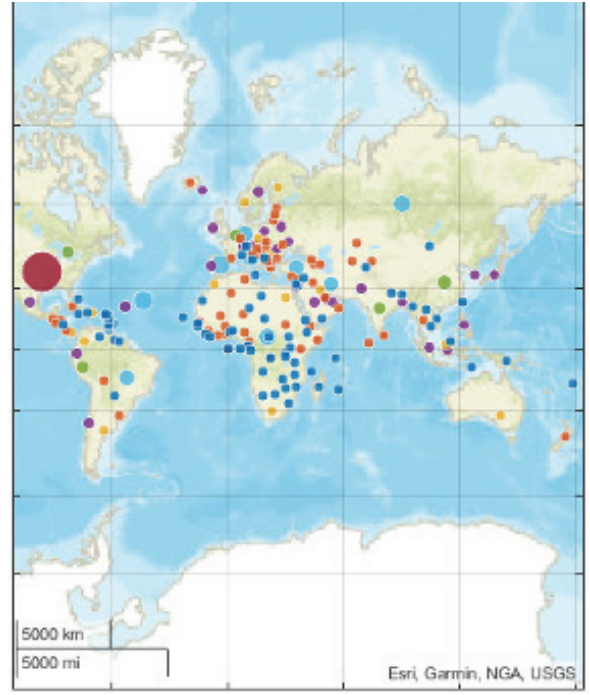

Şekil 1: Dünya genelinde doğrulanmış birikimli vaka sayısı (06 Mayıs 2020 itibariyle).

Artan vakalar ile birlikte, salgını kontrol altına almak amacıyla devlet yönetimleri farklı toplumsal ve ekonomik müdahaleler uygulamışlardır. Bu müdahaleler aslında salgının yayılma şiddetini de etkilemiştir. Örneğin, Çin Hükümeti uyguladığı sıkı toplumsal tedbirler (günler içinde salgın hastanesinin kurulması ve hızlı test uygulama prosedürleri) vaka sayılarında kısa sürede durağan ve sonunda giderek azalan bir eğim yakalamasına neden olmuştur. ${ }^{7,8}$ Şubat ayının başlangıcından beri, COVID-19 salgınının Türkiyede yayılmasını önlemeye ve toplum sağlı̆̆ını korumaya yönelik çeşitli kısıtlama ve müdahaleler uygulanmıştır (Şekil 2). Bütün bunlara rağmen 11 Mart 2020 tarihinde, Türkiyede ilk COVID-19 vakası raporlanmıştır. ${ }^{9}$ Bu vakadan kısa bir süre sonra da, Türkiye dünya genelinde en çok doğrulanmış vakaya sahip ilk 10 ülke arasında yerini almıştır. 


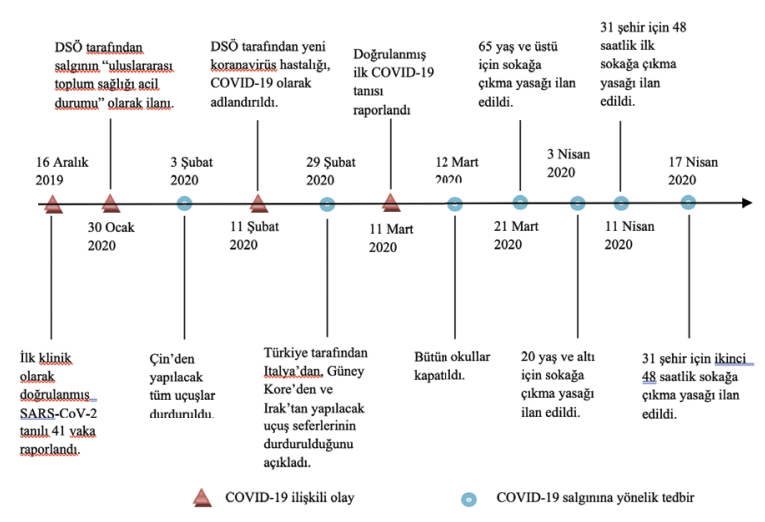

Şekil 2: COVID-19 salgınına ilişkin gelişen olaylar ve Türkiye'de uygulanan önlemlere yönelik zaman çizelgesi.

Salgın süresince belirli zaman dilimlerinde ölümlerin hızını ölçmek amacıyla bir ülkede yaşa ve cinsiyete özgü vaka ölüm oranını tespit etmeye yönelik yapılmış bazı çalışmalar bulunmaktadır. ${ }^{10-12} \mathrm{Bu}$ ölçüm aslında salgının gidişatını ve toplum sağllğ̆ için alınan önlemlerin etkililiğini ortaya koymada bir fikir sağlayabilir. ${ }^{13}$ Örneğin, Almanya’nın pozitif vaka sayısı 164 binden fazla olmasına rağmen, Fransa’da bu durum 135 bin civarındadır. Ancak aynı hastalık nedeniyle gerçekleşen ölüm sayısı sırasıyla yaklaşık 7 bin ve 26 bin civarında olduğu görülmektedir. ${ }^{14}$ Bu bakımdan vaka ölüm oranı halk sağlı̆̆ı açısından salgına yönelik ulusal ve uluslararası stratejilerin yönetiminde kullanılan bir parametre olmasının yanı sıra, 11 hastalık etki değerlendirme ve tahminleme modellerinde de sıklıkla kullanılmaktadır., ${ }^{3,10-12}$ Vaka ölüm oranının yüksek olması sadece sağlık hizmetine tam erişimin kısıtlı olması anlamına gelmeyebilir. Ayrıca vakalara yönelik prevalans çalışmalarının yetersizliği gibi sağlık sistemindeki kısıtlllıklarında var olduğunu ortaya koyabilir. ${ }^{15} \mathrm{Bu}$ bakımdan Türkiye gibi en çok vakaların görüldüğü ülkelerde vaka ölüm oranlarını incelemek hâlihazırda uygulanan çeşitli kısıtlama ve tedbirlerin etki olasılığı belirlenerek bir sonraki koruyucu ve tedavi edici yöntem ve politikaların neler olabileceğinin karar verilmesi bakımından yardımcı olabilir.

Bu nedenlerle, özellikle en çok pozitif vaka görülen ilk 10 ülke içerisinde yer almasından dolayı, Türkiye'deki epidemik parametrelerin, mümkünse yaş grupları bakımından, diğer ülkeler ile karşılaştırılması hastalıkla yapılan mücadelenin etkisini tahminleme ve hastalığın şiddetinin karşılaştırmalı olarak belirlenmesi açısından önemli olabilir. Bu çalışmada öncelikli olarak 6 Mayıs 2020 itibariyle dünya genelinde en çok COVID-19 vakasına sahip ilk 10 ülkedeki epidemik parametreler karşılaştırmalı olarak incelenmiştir. İkinci olarak, bu parametreler Türkiye ile kıyaslanarak benzer duruma sahip ülkeler tespit edilmeye çalışılmıştır.

\section{MATERYAL VE METOD}

Verilerin toplanması

$\mathrm{Bu}$ çalışma için gerekli olan ilgili COVID-19 veriler John Hopkins Üniversitesi tarafından uluslararası düzeyde düzenlenen veritabanından elde edilmiştir. ${ }^{16}$ Ayrıca söz konusu veriler, Dünya Sağlık Örgütü (DSÖ) tarafından günlük olarak yayınlanan durum raporları ile teyit edilmiştir. ${ }^{17}$ Çalışmada kullanılan veriler, kamuoyuna açık kaynaklarda yer aldığından herhangi bir etik onam alınmamıştır.

Araştırma kapsamında yer alan 10 ülkeden elde edilen veriler, ilk vakanın tespit edilmesinden itibaren 6 Mayıs 2020 tarihine kadar olan birikimli vaka sayılarını kapsamaktadır. Dolayısıyla her ülkedeki doğrulanmış ilk vaka bildirim tarihleri farklılık göstermektedir. Bu ülkeler sırasıyla, Amerika Birleşik Devletleri, İspanya, İtalya, İngiltere, Rusya, Fransa, Almanya, Türkiye, Brezilya ve İran'dan oluşmaktadır (Tablo 1). 
Tablo 1: Doğrulanmış ilk vaka tarihinin ve 57.günde rapor edilen vaka tarihinin ülkelere göre karşılaştırılması.

\begin{tabular}{|l|c|c|}
\hline Ülkeler & İlk vaka rapor tarihi & $\begin{array}{c}\text { 57.gün rapor edilen } \\
\text { vaka tarihi }\end{array}$ \\
\hline $\begin{array}{l}\text { Amerika Birleşik } \\
\text { Devletleri }\end{array}$ & 22 Ocak 2020 & 18 Mart 2020 \\
\hline İspanya & 01 Şubat 2020 & 28 Mart 2020 \\
\hline İtalya & 31 Ocak 2020 & 27 Mar 2020 \\
\hline İngiltere & 31 Ocak 2020 & 27 Mart 2020 \\
\hline Rusya & 31 Ocak 2020 & 27 Mart 2020 \\
\hline Fransa & 24 Ocak 2020 & 20 Mart 2020 \\
\hline Almanya & 27 Ocak 2020 & 23 Mart 2020 \\
\hline Türkiye & 11 Mart 2020 & 06 Mayıs 2020 \\
\hline Brezilya & 26 Şubat 2020 & 22 Nisan 2020 \\
\hline İran & 19 Şubat 2020 & 15 Nisan 2020 \\
\hline
\end{tabular}

\section{Verilerin Analizi}

Tanımlayıcı nitelikte olan bu çalışmada, her bir ülkenin pozitif vaka sayısı ve bu sebepten ölen kişi sayısı birikimli olarak hesaplanmıştır. Çalışmanın geçerliliği için, Türkiye’de ilk vakanın rapor edildiği 11 Mart 2020 tarihinden 6 Mayıs 2020 tarihine kadar geçen 57 günlük süre referans alınmıştır. Aynı zaman dilimi içinde tutarlı bir karşılaştırmanın yapılabilmesi için öncelikle her ülkenin ilk vaka raporlama tarihleri tespit edilmiştir. Daha sonra araştırma kapsamında yer alan ülkelerin ilk pozitif vaka rapor tarihinden itibaren 57 günlük sürede meydana gelen doğrulanmış vaka sayısı, buna bağlı ölüm sayıları ve iyileşen hasta sayıları çalışmaya dahil edilmiştir. Ayrıca 6 Mayıs 2020 tarihi itibariyle en çok vaka görülen ilk 10 ülkede doğrulanmış vaka ve ölüm sayıları tespit edilerek, ikinci bir zaman dilimi olarak değerlendirilmiştir. Böylece ülkelerin ilk 57 günlük vaka ölüm oranlarının en güncel tarihteki oranları ile karşılaştırılarak salgının ülkelerdeki salgın şiddeti tahminlemeye çalışılmıştır. Ülkelerin vaka ölüm oranının yüzde olarak tespiti için şu formül kullanılmıştır:

(Ülkede COVID-19 nedeniyle ölen birikimli kişi sayısı) $\overline{\text { (Klinik olarak doğrulanmış birikimli pozitif vaka sayısı) }}$ x100
Vaka artış oranı olarak tespit edilebilmesi için ise şu formül kullanılmıştır:

((Şimdiki doğrulanmış vaka sayısı)-

$$
\frac{(\text { Bir gün önceki doğrulanmış vaka sayısı) })}{\text { ((Bir gün önceki doğrulanmış vaka sayısı)) }}
$$

Toplanan veriler PRISM v. 8.4 paket analiz programı (Graphpad Software Inc. La Jolla, CA, USA) ile değerlendirilmiştir. Bunun için tanımlayıcı istatistikler kullanılmıştır. İstatistiksel analiz için sürekli değişkenler günlük rapor edilen doğrulanmış pozitif vaka sayısı, toplam doğrulanmış vaka sayısı, birikimli ölüm sayısı ve toplam iyileşen hasta sayısından oluşmaktadır. Değerlendirilen verilerin daha iyi anlaşılması için çalışmada yer alan şekiller PRISM v. 8.4 paket analiz programı ve MATLAB v.R2020a (Natick, Massachusetts: The MathWorks Inc.,USA) simulasyon programı ile görselleştirilmiştir.

\section{BULGULAR}

İlk olarak Aralık 2019 tarihinde Çin'de tespit edildiğinden beri, COVID-19 salgını hızlı bir şekilde dünya genelindeki ülkelere yayılmıştır. DSÖ, 30 Ocak 2020 tarihinde bu salgını uluslararası düzeyde acil toplum sağlığı sorunu olarak ilan ettiği sırada, Amerika Birleşik Devletleri, Fransa ve Almanya gibi birçok ülkede doğrulanmış vaka sayısı rapor edilmeye başlanmıştı. ${ }^{18} 6$ Mayıs 2020 tarihine kadar, Amerika Birleşik Devletleri'nde toplam doğrulanmış vaka sayısı 1 milyonu geçmiştir (Şekil 4). Şekil 3’de görüleceği gibi, Ocak 2020 sonunda dünya genelinde vaka artış ora$\mathrm{n} ı$ aniden yükselerek 1.2'den fazla bir seviyeye ulaşmıştır. Ancak birikimli vaka sayısı 1.500 altında kalmıştır (Şekil 3). Ayrıca şubat ayının ortasında bu oran 0,4 seviyesine çıktıktan sonra 6 Mayıs tarihine kadar giderek azalan bir eğim izlemiştir. En dikkat çekici durum ise dünya genelinde vaka sayısı arttıkça günlük vaka artış oranı düşme eğilimi göstermiştir. 


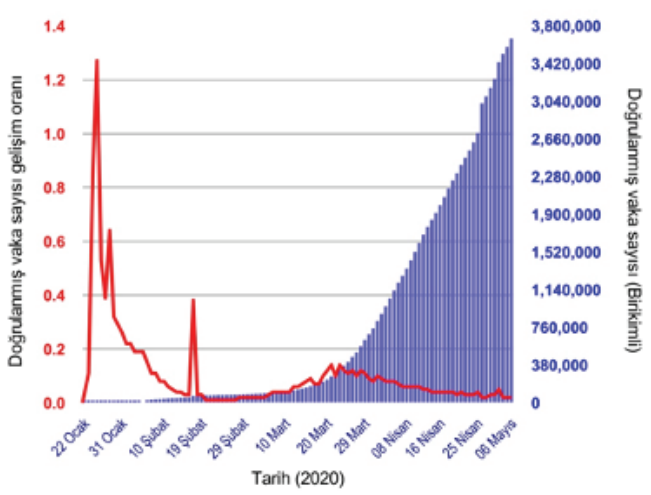

Şekil 3: Dünya geneli doğrulanmış birikimli vaka sayısı ve bunların günlük artışoranı (22 Ocak 2020 ve 06 Mayıs 2020 tarihleri arasinda)

Salgın süresince 22 Ocak 2020 ve 6 Mayıs 2020 tarihleri arasında, en çok vaka rapor edilen ilk 10 ülkedeki doğrulanmış vaka sayıları Şekil 4'de karşılaştırılmıştır. Buna göre, şubat ayı içinde ilk kez bu ülkelerdeki vaka sayısı durağan bir seyir izlemiştir. Şekil 4 daha yakından incelendiğinde, Nisan ayının sonuna kadar Türkiye'deki üstel vaka artış eğrisinin oluşması diğer ülkelere göre uzun zaman almamıştır. Ayrıca epidemik olarak vaka sayısı artış eğrisi özellikle İtalya ve Amerika Birleşik Devletleri ile benzer olsa da, ulusal düzeyde toplam vaka sayıları farklıdır. Şekil 4'de yer alan Amerika Birleşik Devletleri, İngiltere, Fransa gibi birçok ülkede (Türkiye hariç) doğrulanmış vaka artış eğrisi Mart ayının başlangıcına kadar dik bir merdiven şeklini izlemektedir.

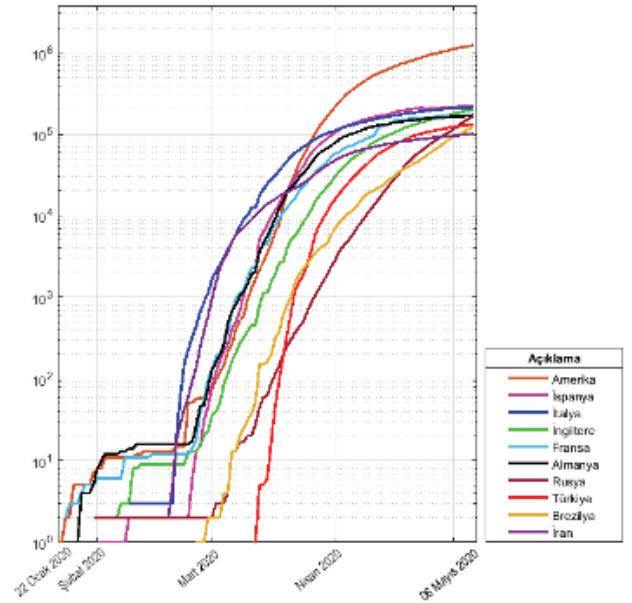

Şekil 4: Doğrulanmış birikimli vaka sayısının en çok rapor edilen ilk 10 ülke için durumu (06 Mayıs 2020 itibariyle)

Türkiye'de ve diğer ülkelerdeki ilk 57 günlük sürede doğrulanmış vakaların karşılaştırmalı artış oranı Şekil 5'de sunulmuştur. Buna göre, diğer ülkelerle karşılaştırıldığında, Türkiye'de doğrulanmış vaka artış oranı ilk hafta aniden yükselerek 4 seviyesine ulaşmıştır. Ancak 3 haftadan sonra bu oran 1 seviyesinin altına düşerek durağan bir ilerleme göstermiştir. Diğer taraftan, İtalya’da 57 günlük sürenin ortasında bu oran 5 seviyesine kadar sıçramış ve daha sonra dalgalı bir şekilde 42 gün sonra giderek azalmıştır. İran'da ise ilk 3 haftalık süreçte vaka artış oranı 3 seviyesinden giderek düşen bir eğilim göstermiştir. Genel olarak değerlendirildiğinde, Türkiye, Brezilya ve İran gibi ülkelerde ilk bir aydan sonraki süreçte vaka artış oranı düz ve yatay bir çizgi olarak devam ederken, aynı zaman diliminde Amerika Birleşik Devletleri, İngiltere, İspanya, Fransa ve Rusya gibi ülkelerde bu oran oldukça değişken bir seyir izlemiştir. Şekil 5'de yer alan ülkeler arasında en yüksek vaka artış oranı İtalyada, en düşük ise Fransada olduğu görülmektedir. 


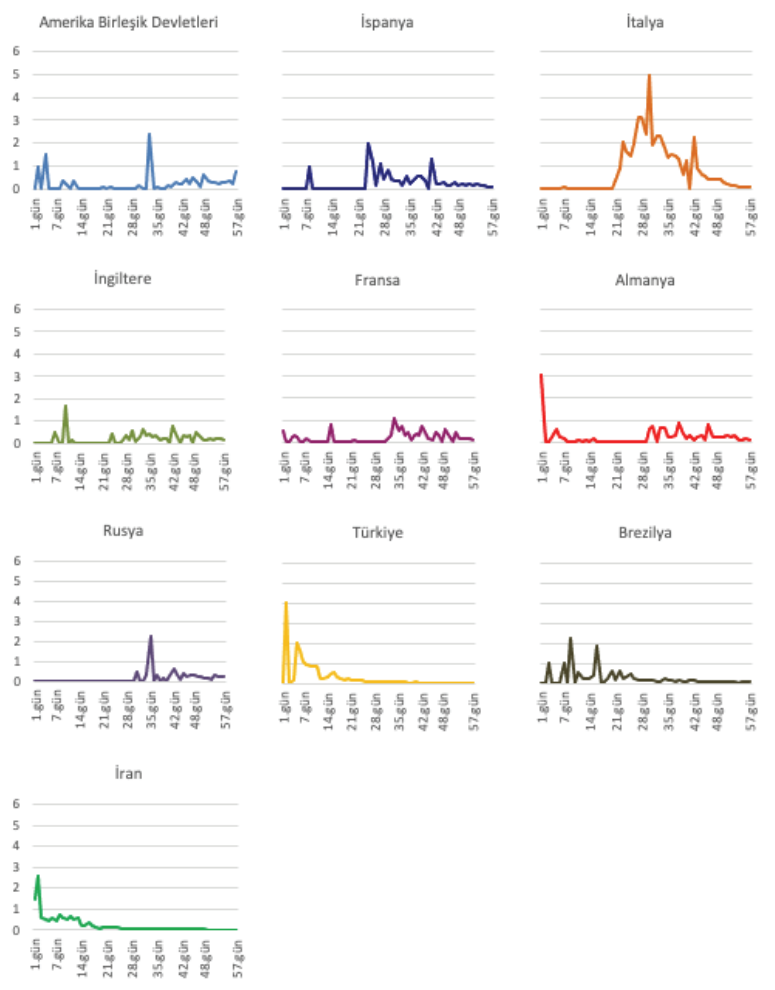

Şekil 5: En çok vaka görülen ilk 10 ülkedeki vaka artı̧soranlarının karşılaştırılması.

Ülkelere göre ilk doğrulanmış vakanın rapor edilmesinden sonraki 57.gündeki ve 6 Mayıs 2020 tarihindeki vaka ölüm oranları ülkelere göre karşılaştırmalı olarak Şekil 6’da gösterilmiştir. Buna göre, bütün ülkelerin (Türkiye hariç) 6 Mayıs tarihindeki vaka ölüm oranları 57.gündeki oranlardan daha fazla olduğu görülmektedir. İtalya, Fransa ve İngiltere’nin 6 Mayıs tarihinde sahip olduğu vaka ölüm oranlarının birbirine çok yakın olması dikkat çekicidir. Çalışma kapsamında yer alan birçok ülkenin (İngiltere, İspanya, Amerika Birleşik Devletleri, İtalya, Fransa, Almanya) 57.gün ve 6 Mayıs tarihlerindeki vaka ölüm oranları belirgin olarak farklı olmasına rağmen, Brezilya, İran ve Rusya gibi ülkelerdeki bu farklılık çok daha azdır. 6 Mayıs 2020 itibariyle en yüksek vaka ölüm oranı \%14,95 ile İngiltere'de, en düşük ise \%0,92 ile Rusya'da olduğu görülmektedir.

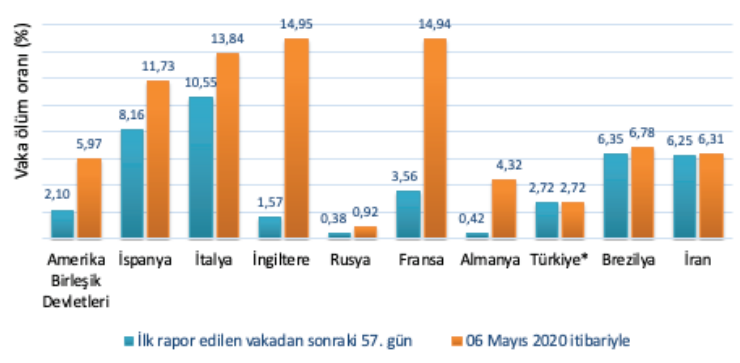

Şekil 6: Türkiye ve diğer ülkelerin vaka ölüm oranlarmın karşılaştırılması.

Şekil 7 ve Şekil 4'de görüldüğü gibi, Amerika Birleşik Devletleri sadece doğrulanmış en çok vakaya sahip ülke değil aynı zamanda salgın nedeniyle ölümlerin en fazla olduğu ülkedir. 6 Mayıs 2020 tarihinde, salgın nedeniyle en az ölü ile birlikte en az iyileșen sayısı da Rusya’da olduğu görülmektedir. Şekil 7’ye göre, en çok vaka görülen ilk 10 ülke arasında Amerika Birleşik Devletleri’nin iyileşen hasta sayısı en fazla olmasına rağmen, İngiltere’nin iyileşen hasta sayısının 344 olması dikkat çekicidir. İyileşen hasta sayısının ölen sayısına olan oranına bakıldığında en yüksek ülkenin Almanya olduğu anlaşılmaktadır.

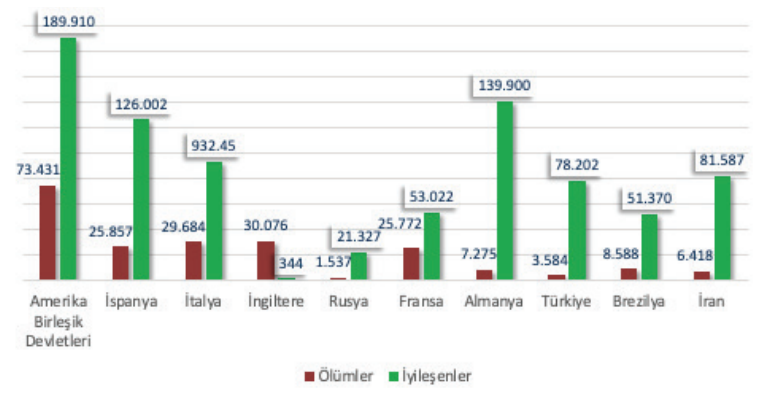

Şekil 7: COVID-19 nedeniyle ölen ve iyileşen hastaların ülkelere göre karşılaştırılması (6 Mayıs 2020 itibariyle)

\section{TARTIŞMA}

COVID-19 salgını, 2019 yılının sonunda Çin, Wuhan'da ortaya çıkmış ve sonrasında kısa sürede çok sayıda ülkeye yayılmıştır. Bu küresel düzeydeki salgına karşı her ülke kendi imkanlarına göre birçok koruyucu ve önleyici tedbirler almıştır. Dünya genelinde salgının ilerleyişini ve uygulanan toplum sağlığı önlemlerinin etkilerini değerlen- 
dirmek için epidemik parametrelerin incelenmesi faydalı olabilir. Bu çalışma, dünya genelinde 6 Mayıs 2020 tarihi itibariyle doğrulanmış en çok vaka rapor edilen ilk 10 ülkeye ait epidemik değişkenleri inceleyerek, bunları Türkiye ile karşılaştırmayı amaçlamıştır.

COVID-19 salgını insandan insana kolay bulaşması nedeniyle DSÖ tarafından pandemi olarak nitelendirilmiştir. ${ }^{19}$ $\mathrm{Bu}$ durumda, toplum sağlığ oluşturacağı riski değerlendirebilmek için enfeksiyonun epidemik artış oranını kullanmışlardır. ${ }^{20}$ Erken dönemde, salgının artış dinamikleri ülkeden ülkeye önemli ölçüde değişiklik gösterebilir. Ancak ilk süreçte, özellikle Ocak 2020 ayında, doğrulanmış birikimli COVID-19 vaka sayısının küresel olarak ani artış göstermesi karar vericilerin salgın yönetiminde izledikleri politikaların muhtemel sonucu olabilir.

Türkiye'deki vaka artış oranlarındaki dalgalanmalar 57 günlük periyodun ortasına kadar devam etmesine rağmen, Amerika Birleşik Devletleri, Fransa ve İngiltere gibi ülkelerde bu durum periyot boyunca devam etmiştir. Ayrıca bu ülkelerdeki doğrulanmış vaka sayıları diğer ülkelere göre daha yüksek olduğu anlaşılmaktadır. Buna göre, enfeksiyonun yayılma hızının azaltılmasına veya durdurulmasına yönelik alınan halk sağlığı önlemlerinin yetersiz ya da yeterince etkili olmadığı düşünülebilir. Diğer taraftan bireylerin de kişisel düzeyde koruyucu önlemleri alması ve bunları benimsemesi de vaka artış oranlarının değişmesine etkisi olacağı değerlendirilmelidir. Çünkü salgına karşı koruyucu ve önleyici sıkı tedbirlerin uygulanması, doğrulanmış vaka sayılarının azalmasına yardımcı olduğu tespit edilmiştir. $^{21}$

Genel olarak ülkelere bakıldığında, 57 günlük zaman sürecinde, \%0,38 (Rusya)'den \%10,55 (İtalya)'e kadar değişiklik gösteren vaka ölüm oranları, 6 Mayıs 2020 tarihindeki değerlerden (\%0,92 Rusya ve \%14,95 İngiltere) daha düşüktür. Bunun olası nedenleri olarak, 1) Çin’de gözlemlendiği gibi, salgının ciddiyeti konusunda farkındalığın eksik olması ve uygunsuz önlemler, ${ }^{22}$ 2) anlamlı çoğunluğun asemptomatik veya hafif belirtiler göstermesi nedeniyle tespit edilememesi, ${ }^{23} 3$ ) özellikle salgının ilk haftalarında COVID-19 test imkanlarının kısitlı olması sonucu pozitif vakaların tespit edilmesinde sıkıntıların yaşanması, ${ }^{24} 4$ ) yaş ve komorbidite gibi faktörler nedeniyle geciken tedavi ya da yetersiz tıbbi araçların erken dönemde daha fazla ölümlere yol açmasi ${ }^{25}$ sayılabilir. Ancak DSÖ tarafından yayınlanan bir rapora göre, asemptomatik ya da çok hafif semptomlu hastaların oranı tam olarak bilinmemesine rağmen, bunların sayısının oldukça az olduğu düşünülmektedir. Dahası, bu grupta olan kişilerin hastalığı bulaştıran asıl faktör olmadığı değerlendirilmektedir. ${ }^{26,27}$

Almanya Robert Koch Enstitüsü kayıtlarına göre, yaklaşık 60 bin ile vakanın en çok görüldüğü yaş grubu 35-59 olmasına rağmen,28 80 yaş ve üzerindeki hastaların vaka ölüm oranı (\%10-12) daha yüksektir. ${ }^{29}$ Amerika Birleşik Devletleri'nde ise vaka ölüm oranı 19 Nisan 2020 itibariyle büyük bir düşüş gösterse de, 75 yaş ve yukarı olan yaş grubu vaka ölüm oranı $(\% 12,66)$ açısından en riskli grubu oluşturmaktadır. ${ }^{30} 70$ yaş ve üstü yaş grubu İtalya'da yaklaşık \%24 vaka ölüm oranı ile en riskli yaş grubunu oluşturmaktadır. ${ }^{31}$ Benzer bir şekilde, İngiltere'de vaka ölüm oranının en yüksek 75 yaş ve üstünde yer alan hastalarda görüldüğü rapor edilmiştir. ${ }^{32}$ Fransa'da diğer ülkelerde olduğu gibi vaka ölüm oranı en yüksek \%10,30 ile 75 yaş ve üstü olduğu bildirilmiştir. ${ }^{33}$ Türkiye’de ise yaş gruplarına göre vaka ve ölüm sayıları resmi olarak açıklanmamıştır.

Türkiye'de 130 binden fazla doğrulanmış vaka ile birlikte vaka ölüm oranının \%2,72 olduğu tespit edilmiştir. $6 \mathrm{Ma}$ yıs 2020 tarihinde, en çok vaka rapor edilen ilk 10 ülke arasında Türkiye vaka ölüm oranının Rusyadan sonra en az olduğu ülkedir. Salgın nedeniyle ilk ölümlerin başladığı ilk haftada (17-23 Mart 2020), Türkiyede vaka ölüm oranı \%1 ve \%2,40 arasında değișmiştir. Aynı periyotta, Çin dışındaki ülkelerdeki ortalama vaka ölüm oranının daha yüksek olduğu tespit edilmiştir. Nisan ayının son haftasında, vaka ölüm oranı Türkiye'de \%2,52'ye, Çin'de ise \%7,04’e 
yükselmiştir. ${ }^{6}$ Vaka ölüm oranlarının giderek arttığı böylesi bir tablo şaşırtıcı olmamıştır. Çünkü dünya genelinde vaka sayıları arttıkça buna bağlı gelişen muhtemel ölüm sayıları da giderek artacaktır. Ayrıca şunu da belirtmek gerekir ki, sağlık sistemine yük olan ve sürdürülebilir tıbbi kaynakları zorlayan pozitif hasta sayısındaki ani artışlar da muhtemel vaka ölüm oranlarının yükselmesine neden olacaktır. COVID-19 hastalığının bulaşma gücü yüksek olmasına rağmen, yaşlı ve diyabet, şeker gibi kronik rahatsızlıkları olan kişileri daha çok etkilediği bilinmektedir.34 $\mathrm{Bu}$ yüzden ülkelerdeki vaka ölüm oranı ile yaş grupları ve kronik rahatsızlığı olan kişiler arasındaki ilişkiyi daha iyi anlamak için sonraki araştırmalarda karşılaştırmalı vaka çalışmaları yapılabilir.

İlk COVID-19 vakasının Çin'de rapor edildiği Aralık 2019 tarihinden beri, 6 Mayıs 2020 tarihinde dünya genelinde 3,5 milyondan fazla doğrulanmış birikimli vaka ve 250 bine yakın ölüm rapor edilmiştir. ${ }^{35}$ Ancak, Şubat ayının ilk haftasından itibaren toplam iyileşen hasta sayısı ölen sayısını geçmeye başlamıştır. ${ }^{36}$ Bu durum ilk olarak Türkiye’de ilk vakanın rapor edilmesinden 20 gün sonra 214 ölen kişiye rağmen 243 iyileşen hasta olarak meydana gelmiştir. Amerika Birleşik Devletleri (68 gün sonra), İspanya (36 gün sonra) ve İtalya (28 gün sonra) ise bu eğilimi salgın süresince farklı zamanlarda yakalamıştır. Ayrıca vurgulamak gerekir ki, Türkiye’de dahil diğer ülkelere göre, Almanya’da iyileşme-ölüm oranı en yüksek seviyededir. Türkiye’de bu oran daha ılımlı gibi görünmesine rağmen, İngiltere'de ise oldukça düşüktür. Genel olarak iyileşme-ölüm oranının yüksek olmasının altında yatan sebepler arasında, yaygın ölçüde tanı testlerinin uygulanması, salgın süresince erken koruyucu halk sağlığı önlemlerinin uygulanması, COVID-19 hastalarının yükünü kaldırabilecek güçlü bir sağlık sistemi sayılabilir.

Çalışmada bazı kısıtlılıkların olması nedeniyle, sonuçların değerlendirilmesinde bunların dikkate alınması gerekmektedir. İlk olarak, Türkiye'de dahil olmak üzere pozitif vakalara yönelik veriler laboratuvar sonucuyla doğrulan- mış bilgilerden oluşmaktadır. Dolayısıyla, asemptomatik veya hafif belirtiler gösteren vakalar ${ }^{37}$ çalışmaya dahil edilmemiştir. İkinci olarak, COVID-19 hastalığının tipik bulguları (ateş, kuru öksürük, yorgunluk hissi, nefes darlığı, boğaz ağrısı, baş ağrısı, burun tıkanıklığı, miyalji veya artralji $)^{26,37}$ ile birlikte göğüs tomografi sonucu da bunu destekler nitelikte olmasına rağmen enfeksiyon laboratuvar sonucu negatif olan hastaların kümülatif vaka sayısına dahil edilmediği düşünülebilir. Son olarak, risk altında olan ve şüpheli bulunan vakaların sürveyans takip uygulamaları ülkelere göre farklı olabileceğinden günlük rapor edilen vaka sayısı da bundan etkilenebilir.

Her ülkenin sahip olduğu sosyal, ekonomik ve gelişmişlik düzeyinin yanında sağlık sistemindeki imkân ve kabiliyetler ölçüsünde küresel boyuttaki COVID-19 salgınından etkilenmektedir. Salgının toplum sağlığı boyutu göz önüne alındığında, sonraki dönemlerde de etkilerinin devam edeceği, artış oranının ülkelerin uygulayacağı önlem ve politikalara göre farklılık gösterebileceği değerlendirilmelidir. COVID-19 enfeksiyonuna özgü aşılama ve hâlihazırda etkili bir tedavi yöntemi olmadığı için bulaşmaya karşı kişisel olarak korunmak önemlidir. Özellikle karar vericilerin daha etkili vaka gözlem, takip ve kontrol sistemleri oluşturarak toplumsal ve bireysel düzeyde hastalığın etkilerini azaltmak için önlemler alması faydalı olabilir. 


\section{Kaynaklar}

1. Qun Li M, Guan X, Wu P, et al. Early Transmission Dynamics in Wuhan, China, of Novel Coronavirus-Infected Pneumonia. N Engl J Med. 2020;382:1199-1207. doi:10.1056/NEJMoa2001316

2. World Health Organization (WHO). Coronavirus Disease (COVID-19) Situation Report - 106.; 2020. https://www.who.int/docs/default-source/coronaviruse/situation-reports/ 20200505covid-19-sitrep-106.pdf?sfvrsn=47090f63_2. (Erişim: 5 Mayıs 2020).

3. Verity $R$, Okell LC, Dorigatti I, et al. Estimates of the severity of coronavirus disease 2019: a model-based analysis. Lancet Infect Dis. 2020;3099(20):1-9. doi:10.1016/ S14733099(20)30243-7

4. World Health Organization (WHO). Coronavirus disease 2019 (COVID-19) Situation Report - 37. https://www.who.int/docs/default-source/coronaviruse/situation-reports/20200226-sitrep-37-covid-19.pdf?sfvrsn=2146841e_2. (Erişim: 1 Mayıs 2020).

5. World Health Organization (WHO). Coronavirus disease 2019 (COVID-19) Situation Report - 96. https://www.who.int/docs/default-source/coronaviruse/situation-reports/20200425-sitrep-96-covid-19.pdf?sfvrsn=a33836bb_2. (Erișim: 4 Mayls 2020).

6. Covid-19 interactive dashboard. The Center for Systems Science and Engineering (CSSE) at Johns Hopkins University. https://www.arcgis.com/apps/opsdashboard/index.html\#/ bda7594740fd40299423467b48e9ecf6. (Erişim: 6 Mayıs 2020).

7. BBC News. Coronavirus: How can China build a hospital so quickly? https://www.bbc.com/ news/world-asia-china-51245156. (Erişim: 8 Mayıs 2020).

8. Wong S, Vaughan A CQ-HL. Covid-19 news: US not involved in global WHO plan to tackle pandemic. Health (Irvine Calif). 2020. https://www.newscientist.com/article/2237475-covid-19-news-us-not-involved-in-global-who-plan-to-tackle-pandemic. (Erişim: 10 Mayıs 2020).

9. World Health Organization (WHO). Coronavirus disease 2019 (COVID-19) Situation Report - 52. https://www.who.int/docs/default-source/coronaviruse/situation-reports/20200312-sitrep-52-covid-19.pdf?sfvrsn=e2bfc9c0_4. (Erişim: 7 Mayıs 2020).

10. Onder G, Rezza G, Brusaferro S. Case-Fatality Rate and Characteristics of Patients Dying in Relation to COVID-19 in Italy. JAMA - J Am Med Assoc. 2020;2019:2019-2020. doi:10.1001/jama.2020.4683

11. Rajgor DD, Lee MH, Archuleta S, et al. The many estimates of the COVID-19 case fatality rate. Lancet Infect Dis. 2020;3099(20):30244. doi:10.1016/S1473-3099(20)30244-9

12. Porcheddu R, Serra C, Kelvin D, et al. Similarity in Case Fatality Rates (CFR) of COVID-19/ SARS-COV-2 in Italy and China. J Infect Dev Ctries. 2020;14(2):125-128. doi:10.3855/ jidc. 12600

13. Zeegers MP, Bours MJL, Freeman MD. Methods Used in Forensic Epidemiologic Analysis. In: Forensic Epidemiology. Elsevier; 2016:71-110. doi:10.1016/B978-0-12-404584-2.000033

14. World Health Organization (WHO). Coronavirus disease (COVID-19) Situation Report108. https://www.who.int/docs/default-source/coronaviruse/situation-reports/20200506covid-19-sitrep-107.pdf?sfvrsn=159c3dc_2. (Erișim: 2 Mayıs 2020).

15. World Health Organization (WHO). Cholera case fatality ratio (\%). https://www.who.int/ gho/epidemic_diseases/cholera/situation_trends_case_fatality_ratio/en/. (Erișim: 3 Mayls 2020).

16. Dong E, Du H, Gardner L. An interactive web-based dashboard to track COVID-19 in real time. Lancet Infect Dis. 2020;20(5):533-534. doi:10.1016/S1473-3099(20)30120-1

17. World Health Organization (WHO). Coronavirus disease (COVID-19) situation reports. https://www.who.int/emergencies/diseases/novel-coronavirus-2019/situation-reports. (Erișim: 11 Mayts 2020).

18. World Health Organization (WHO). Statement on the second meeting of the International Health Regulations (2005) Emergency Committee regarding the outbreak of novel coronavirus (2019-nCoV). Geneva, Switzerland. https://www.who.int/news-room/detail/30-01-2020-statement-on-the-second-meeting-of-the-international-health-regulations-(2005)-emergency-committee-regarding-the-outbreak-of-novel-coronavirus-(2019-ncov). (Erişim: 3 Mayıs 2020).

19. World Health Organization (WHO). WHO Director-General's opening remarks at the media briefing on COVID-19 - 11 March 2020. https://www.who.int/dg/speeches/detail/whodirector-general-s-opening-remarks-at-the-media-briefing-on-covid-19---11-march-2020. (Erişim: 4 Mayıls 2020).
20. Ganyani T, Roosa K, Faes C, et al. Assessing the relationship between epidemic growth scaling and epidemic size: The 2014-16 Ebola epidemic in West Africa. Epidemiol Infect. 2019;147. doi:10.1017/S0950268818002819

21. Du W, Han S, Li Q, Zhang Z. Epidemic update of COVID-19 in Hubei Province compared with other regions in China. Int J Infect Dis. 2020. doi:10.1016/j.ijid.2020.04.031

22. Novel Coronavirus Pneumonia Emergency Response Epidemiology Team. The epidemiological characteristics of an outbreak of 2019 novel coronavirus diseases in China. Honghua Liu Xing Bing Xue Za Zhi. 2020;41(2):145-151. doi:10.3760/cma.j.issn.0254-6450.2020.02.003

23. Deng S-Q, Peng H-J. Characteristics of and Public Health Responses to the Coronavirus Disease 2019 Outbreak in China. J Clin Med. 2020;9(2):575. doi:10.3390/jcm9020575

24. Hellewell J, Abbott S, Gimma A, et al. Feasibility of controlling COVID-19 outbreaks by isolation of cases and contacts. Lancet Glob Heal. 2020;8(4):e488-e496. doi:10.1016/S2214109X(20)30074-7

25. Fang Y, Nie Y, Penny M. Transmission dynamics of the COVID-19 outbreak and effectiveness of government interventions: A data-driven analysis. J Med Virol. 2020;(March). doi:10.1002/jmv.25750

26. World Health Organization (WHO). Report of the WHO-China Joint Mission on Coronavirus Disease 2019 (COVID-19). Vol 1.; 2020. https://www.who.int/docs/default-source/coronaviruse/who-china-joint-mission-on-covid-19-final-report.pdf. (Erișim: 10 Mayıs 2020).

27. The Novel Coronavirus Pneumonia Emergency Response Epidemiology Team. The Epidemiological Characteristics of an Outbreak of 2019 Novel Coronavirus Diseases (COVID-19) - China. China CDC Wkly. 2020;2(8):113-122. doi:10.46234/ccdcw2020.032

28. Robert Koch-Institut: COVID-19-Dashboard. https://experience.arcgis.com/experience/478220a4c454480e823b17327b2bfld4. (Erişim: 8 Mayıs 2020).

29. Coronovirus Disease 2019 (COVID-19) in the EU/EEA and the UK - Eighth Update. Rapid Risk Assessment.; 2020. https://www.ecdc.europa.eu/sites/default/files/documents/ covid-19-rapid-risk-assessment-coronavirus-disease-2019-eighth-update-8-april-2020.pdf. (Erişim: 9 Mayıs 2020).

30. Centers for Disease Control and Prevention Report. Provisional Death Counts for Coronavirus Disease (COVID-19).; 2020. https://www.cdc.gov/nchs/nvss/vsrr/COVID19/. (Erişim: 3 Mayıs 2020).

31. Prodotto dall'Istituto Superiore di Sanità. Epidemia COVID-19. Roma, ITALY; 2020. https://www.epicentro.iss.it/coronavirus/bollettino/Bollettino-sorveglianza-integrata-COVID-19_30-marzo-2020.pdf. (Erişim: 6 Mayıs 2020).

32. Office for National Statistics. Deaths registered weekly in England and Wales, provisional: week ending 3 April 2020. https://www.ons.gov.uk/peoplepopulationandcommunity/birthsdeathsandmarriages/deaths/bulletins/deathsregisteredweeklyinenglandandwalesprovisional/weekending3april2020/pdf. (Erişim: 9 Mayıs 2020).

33. Fatality rate of the novel coronavirus COVID-19 in France by age group. https://www.statista.com/statistics/1104969/china-wuhan-coronavirus-covid-19-fatality-rate-by-age-group/. (Erişim: 4 Mayıs 2020).

34. Older people are at highest risk from COVID-19, but all must act to prevent community spread. http://www.euro.who.int/en/health-topics/health-emergencies/coronavirus-covid-19/statements/statement-older-people-are-at-highest-risk-from-covid-19,-but-allmust-act-to-prevent-community-spread. (Erişim: 2 Mayıs 2020).

35. World Health Organization (WHO). Coronavirus disease (COVID-19) Situation Report 107. https://www.who.int/docs/default-source/coronaviruse/situation-reports/20200506covid-19-sitrep-107.pdf?sfvrsn=159c3dc_2. (Erişim: 3 Mayıs 2020).

36. Johns Hopkins Center for Systems Science and Engineering. Coronavirus COVID-19 global cases. $\quad$ https://data.humdata.org/hxlproxy/api/data-preview.csv?url=https $\% 3 A \% 2 F \% 2 F$ raw.githubusercontent.com\%2FCSSEGISandData\%2FCOVID-19\%2Fmaster\%2Fcsse_covid_19_data\%2Fcsse_covid_19_time_series\%2Ftime_series_covid19_confirmed_global. csvéfilename=time_series_covid19_confirmed_global.csv. (Erişim: 10 Mayıs 2020).

37. Huang C, Wang Y, Li X, et al. Clinical features of patients infected with 2019 novel coronavirus in Wuhan, China. Lancet. 2020;395(10223):497-506. doi:10.1016/S01406736(20)30183-5 